\title{
Planning to Improve the Quality of Basic Education
}

\author{
Lina Zhang \\ Teachers' College Shenyang University \\ Shenyang, China
}

\author{
Zhiqing Liu \\ Beijing Normal University \\ Beijing, China
}

\begin{abstract}
The issue of the quality education is gradually becoming more an area of focus and anxiety to many countries all over the world, especially in the developing ones. This is because many countries in the developing world have realized that education plays a decisive and crucial role in development at national, regional and international levels. It is very clear that the level of educational development in developing countries is much lower than developed countries of the world. There is interest in the issue of quality because it is an integral part of the development and monitoring of education systems. There cannot be any argument about the fact that the issue of quality in education has become an important issue and the demand to improve the quality of education is articulated frequently in contemporary educational reforms worldwide. It is precisely as this happens that the need to consider the quality of what is provided in schools becomes a higher priority than simple quantitative improvements (Garrett 1999: 27).
\end{abstract}

Keywords—quality; basic education; improvement; planning

\section{INTRODUCTION}

This paper attempts to highlight some points, which have been, and can be used, to improve basic educational quality with specific reference to planning improvement in relation to contemporary Chinese Basic Education. It also attempts to raise awareness of the importance and value of the development of quality in basic education worldwide, especially in the developing world.

The outline of the paper is as follows: Section One is devoted entirely to the discussion about quality of education. Its focus is on the different definitions and interpretations of forms and meanings. Section Two introduces a review of the literature concerned with proposals on improvement of educational quality. Section Three describes basic education in China with particular reference to its aims and how it is organized. Shortcomings in basic education are discussed. Section Four begins with brief background information about the need for improvement, then attempts to discuss the planning of this improvement towards the quality of basic education in China. The last section brings us to the conclusion of the study, relating the evidence drawn from the literature and the findings from the case of China.

\section{QUALITY IN BASIC EDUCATION}

In order to discuss how to plan to improve quality in basic education, it is necessary to define the terms of basic education and quality. In much contemporary discourse on education, both basic education and quality are frequently mentioned, although they mean different things to different people.

\section{A. Basic Education}

In the context of this paper, 'basic education' means the general education provided for each children-age group in its entirety. It is intended for children from seven to sixteen years of age, and its completion incomprehensive school takes nine years. After completing comprehensive school, pupils have fulfilled their compulsory education. (EDUfi.2002).

\section{B. Quality of Education}

The notion of quality of education is more problematic because different aspects of education can be focused on when it is defined. It is a multi-faceted, all-encompassing concept or attributes (Murimba, 2002 cited in Makwati el at. 2003:9). Here are several ways of interpreting 'quality' in education.

A voice from UNESCO Regional Office for Education takes the term 'quality' as pupil performance or standards of attainment in different school subjects (UNESCO 1982:62). In this sense, decline in the quality of education means the standards of attainment have gone down, through examination results or other norms of scholastic achievement. Hawes and Stephens (1990:1 1\&22) tend to give a more comprehensive definition of quality, implying efficiency in meeting set goals (e.g. better use of available resource); relevance to human and environmental needs and conditions (e.g. to needs and contexts) as well as 'something more' in relation to the pursuit of excellence and human betterment (e.g. to journey a little further than mere deficiency and relevance). Malaysia echoes with a useful operational definition of quality of education as 'the capability of the education system to meet desired standard in terms of relevance in its curriculum, effectiveness and efficiency in the delivery as well as equality in opportunities for all' (Commonwealth Secretariat 1991: 3). Another voice from the Commonwealth Secretariat regards the quality of education as the value and goals of that country's social system and culture, and in terms of the policies, objectives and practices of its education system (Commonwealth. Secretariat 1991: 6). In this sense, it refers not only to the economic needs of society but also to promote culture and values. In addition, Kellghan argued that quality of education relates to the adequacy or appropriateness of objects or processes for the purposes for which they were intended 
(Kellaghan, 2001: 22). Here 'good' or 'poor' quality depends on an object or processes of purposes, which can be met or fail to be met. In current reform proposals, the outcomes of education have been focused on as the key standard of quality of education, according to the different roles of education, such as fostering students' cognitive, moral, and social development, preparation for the world of Work, also the promotion of social and national cohesion.

\section{LITERATURE ON THE IMPROVEMENT OF QUALITY OF BASIC EDUCATION}

\section{A. Why is Quality of Education Important?}

Firstly, at the international level, the World Conference on Education for All, held in Jomtien, Thailand in 1990, has affirmed the imperative not only to ensure education for all children but also to offer education of an acceptable standard for all, which should meet the current and future needs of the learners. More recently, in 2002, at the meeting in Dakar, Senegal, the issue of quality was revisited and stated that:

The Dakar framework for Action gave new impetus to the promotion of quality in education, based on the consensus that expanding access to education will have a beneficial impact on individuals and on society only if the education is of good quality. (UNESCO, 2002: 80)

Secondly, at the national levels, the importance of quality in education has been acknowledged as a key aspect in the improvement of general development. Undoubtedly education is a cornerstone of economic and social development and basic education is its foundation (Lockheed, E.M. el at 1991:1). Good quality of education is the lifeline of educational development low quality in schooling can hinder any long-term benefits that may generate from existing schooling. Fuller (1 986) expands upon this theme:

Growing interest in school quality also stems from research emphasizing that the economic benefits of more schooling are limited by low levels of school quality and student achievement. Recent evidence suggests...economic returns to school depend not only on length of school but also on the level of actual learning that occurs (Fuller 1986: 493 cited in Garrett 1999:26)

In addition, many countries regard the establishment of national unity and cultural identity as one of the educational objectives. It reveals that the quality of education is responsible for the development of society and culture. Furthermore, leaders in many countries consider the quality of education as a means of keeping abreast with scientific and technological advance to enhance the national competitiveness.

Thirdly, at the individual level, parents realize that the quality of schooling impact significantly on their children's quality of life and their future life chances because of the high rate of return in education, particularly in developing nations.

It is obvious that the quality of education is concerned with every part of society from international, national and down to the level of the individual. Thus, searching for the ways in which to access a good quality of basic education and planning to improve it should become the priority of educational reforms worldwide.

\section{B. Strategies on the Improvement of Quality of Basic Education}

In the year of 2001, in Dakar, Senegal, the question of improving educational quality was raised during the World Education Forum, 'How-to improve quality and performance in universal compulsory education to meet the fundamental goal of lifelong learning for all through sustainable measures' With this aim in mind, and in order to promote good quality universal compulsory education, many educators and educational specialists around the world identified strategies that would lead to the improvement of the quality of basic education.

Garrett (1999) argued that if the quality of education is to be improved, at least seven distinct but interrelated areas have to be addressed, which are: teachers, children, management, resources, curriculum, infrastructure and community (Garrett, R 1999:31). In addition, Stephens (2003) summarized six major commendations for improving the quality-of education, they are: emphasis on learning, invest in what works cost - effectively, improve the next generation of teachers, improve management, expand equitable access and finance improvements (Stephens, D. 2003: 26-28). Furthermore, another voice from Expels 'Meeting on improving performance in Primary education is that if countries take the findings seriously, by the end of 2015 schools would have provided one billion literate adults, curriculum, an enabling environment for learning, support systems, governance in primary education as well as assessment and evaluation (UNESCO 2003: 10-12). In the light of the above, it is urgent and necessary for all educators and actors to develop strategies for the measurement, evaluation and management of the quality of education at international, regional and country levels. Below is an input - process - output framework for assessing educational quality, presenting a model of the real process of development of quality in education.

This framework can guide a step-by-step assessment of educational quality for various stakeholders in education (1earners, teachers, parents, communities and government) at the various levels (classroom, school, national policy) in "Fig. $1 "$.

Indicators of the overall improvement of educational quality mentioned above are essential for establishing the goals and policies, as well as guiding and underpinning the work concerning schools, teachers, and students. It also provides policy-makers a foundation for planning education. Last but not least, because there is always a gap between criteria and reality, the implementation of these indicators must vary greatly according to the different circumstances. Just as Smith (1997) suggested that all quality relates to the context in which it is being considered and this in turn alters with time, thus progression is of vital regard (Smith, 1997 cited in Garrett, R. 1999: 53). Therefore, quality in education differs from country to country and each 
country has to plan and determine its own priorities in order

to improve the quality of their own education.

INPUT

PROCESS

OUTPUT

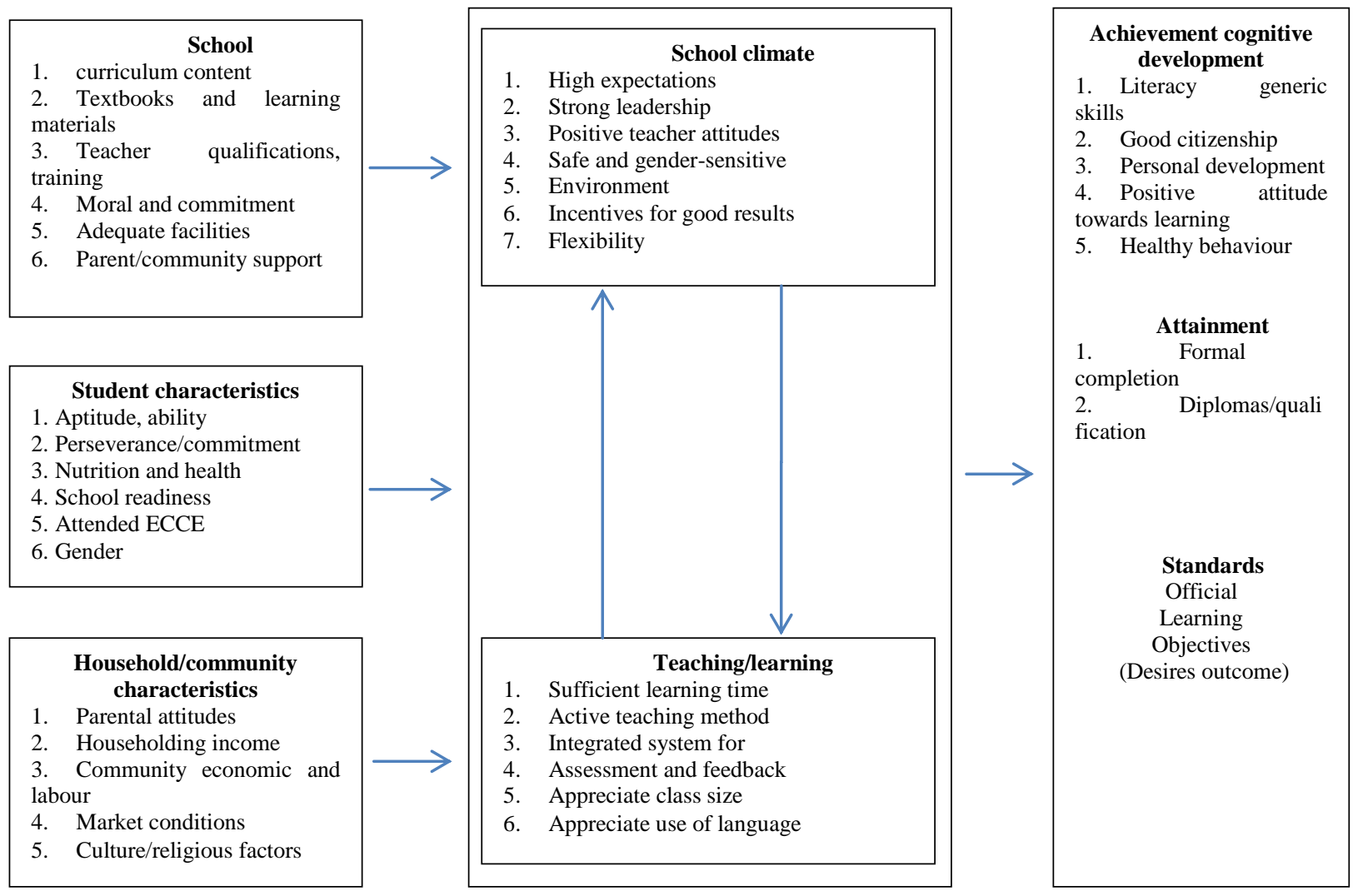

\section{Contextual factors}

1. Macro-economic and fiscal policies, political stability, decentralization and govern service quality.

2. National goals and standards for education, curricular guidelines, sources of fund allocation, teacher recruitment/development

3. Education system management

4. Participation, progression, completion and transition

5. Engagement and use of time

6. Peer effects, parental support, and promotion policies

Fig. 1. An input-process-output framework for assessing education quality.

\section{A CASE STUDY-PLANNING TO IMPROVE QUALITY OF BASIC EDUCATION IN CHINA}

\section{A. Overview of Basic Education in China}

Basic education in China generally comprises primary education of 6 years and secondary education of 3 years (junior) and a further 3 years (senior).Compulsory education includes the primary and junior secondary level.

China's reform and opening up since 1978 has brought the basic education into a new period of development. On National Day in 1983, it was stated "Education should serve the modernization drive while gearing to the world and future" provided a guiding principle for the future strategy of educational development. In 1985, the central authorities adopted the decisions to reform the educational system and the Compulsory Education Law, enacted in 1986, stipulates
${ }^{\text {a. }}$ Source: UNESCO 2002: 81 EFA Monitoring Report that all children should receive 9 years of compulsory education, which is believed to be a cornerstone in development of China's educational cause. In 1995 China proclaimed the "strategy for national development through science and education" concerning the acceleration of scientific and technological progress. In 1999, the State Council approved 'Action Plan for Invigorating Education in the 21st Century' and passed the decisions on bringing educational reform in depth, with the aim of improving the educational quality.

\section{B. Issues in Chinese Basic Education}

China has the largest primary and junior secondary education system in the world. Compared with other developing countries, it has made remarkable progress to its population in achieving universal compulsory education. According to the official statistics, by the end of 2003 , 
98.65\% of school-age children were enrolled in primary schools: $97.9 \%$ of primary school students went on to junior secondary and dropout rate was $0.34 \%$. The enrollment of junior secondary schools has reached $92.7 \%$, and the dropout rate was $2.84 \%$ and $59.6 \%$ of junior secondary students went on to senior secondary schools (Ministry of Education, ER. C. 2004).

However, gaps are continuing or widening between the eastern and coastal and the western regions, between rural and urban within the western region. While the goal of nineyear compulsory education is already achieved and senior secondary education has already been made universal in most large cities and coastal areas, many poor and remote Areas have not even reached universal primary education. In addition, the decentralization policy has motivated the local authorities in better-off areas to raise funds in multiple ways, but it has put great pressure on the poor regions where local resources are limited and which suffer from insufficient classrooms and schools, inadequately trained teachers, inadequate teaching materials, higher than average dropout and repetition rates, also unsatisfactory management and difficult access. As a result, the disparities between regions have enlarged in many cases.

Obviously, the low quality of basic education and the poverty of the areas are intertwined and the need for planning to improve quality of education in the western regions in China is becoming more urgent and imperative.

\section{Planning to Improve Quality in Basic Education in Western Region and Rural Areas of China}

On March 3, 2004, the State Council approved and disseminated the 2003-2007 Action Plan for Invigorating Education. This Plan is the fundamental blueprint to further implement the strategies of 'Rejuvenating China through Science and Education'. In the new Action Plan, universalizing the nine-year compulsory education and improving the quality of compulsory education in the rural and western areas was the priority among priorities in developing education. The plan objectives will be achieved by planning for improving educational resources, improving management of schools and educational systems as well as facilitating innovative actions in the educational system.

1) Planning for finance and resources: It is generally accepted that the most common cause that has hampered the effort at enhancing the quality of education is inadequate funding. Inadequate funding inevitably leads to an insufficient supply of all types of inputs to the education system, such as adequate facilities, teacher qualifications and training, curriculum content, textbooks and learning materials, etc. (the box of Figure 1). Thus, the provision of adequate resources to schools is, to a great extent, a decisive factor in the quality of education. In China, some 64 percent of China's population live in poor western and rural areas, in order to fulfill the objectives, Education Minister Zhou Ji pledged China will allocate more funds from the central budget to these areas, with 10 billion Yuan (US\$1. 2 billion)each year (China Development Gateway 2004). In 2003, 3 billion Yuan was allocated by the Central Government as a special fund to support compulsory education in impoverished areas ; 2 billion Yuan, out of a planned 6 billion Yuan, was spent on the renovation of dilapidated school buildings ; 1.4 billion was used for modern facilities for remote education; expenses for free textbooks have been increased from 200 million Yuan to 400 million Yuan allotted by the Central Government (ibid).

2) Planning for the management system of education: Among the indicators of the overall improvement of educational quality, an efficient and effective educational management system as a contextual element is recognized to be fundamental to quality of education. Management performs a number of key functions in strengthening educational quality, such as ensuring implementations of national policies and directives, ensuring an adequate allocation of necessary resources, proving teachers and principals with material, innovative and professional support, as well as identifying the task of monitoring and evaluation of meeting the goals etc. In China, local governments are responsible for policies and regulations for leadership as well as the management and inspection of schools, but they have no regulations stipulating the qualifications for key educational administrators. Thus the quality of the management mainly relies on the experience and educational background of the individuals in charge. To ensure the improvement of the rural compulsory education, the new management system focuses on the county government taking the principal responsibility. The improvement of the quality of management in education is fostered through the establishment of training modes to support principal, provincial and county educational management, education planners, and project management training, upgrading the competence of school, county, provincial and national level managers.

3) Planning for teacher training: Undoubtedly, good teachers are the key to good education (Garrett, 1999: 3 1). Bacchus gave more clear evidence and suggested that more innovative teaching strategies need to be developed as part of the armory in providing better quality education. In fact, both the quantity and quality of teachers largely determine how good education will be. Without adequate and welltrained teachers, the educational quality cannot be improved and only remain low. In most parts of the western and rural areas of China, teachers are in an acute shortage and a number of teachers in the schools are unqualified. In the New Action, China has given teacher training a high priority in the poor regions. To attract and motivate more committed teachers, China plans to allocate more funds from the central budget to pay for approximately 78 percent of local teachers' salaries (China Development Gateway 2004). Furthermore, to improve the teachers' quality in these poorer areas, in addition to upgrading the unqualified teachers to meet officially required qualification levels, 
many more teachers are to be trained to upgrade their skills and approaches periodically to meet the ongoing curriculum reform. In addition, the National programme of United Network for education of teachers, which started in 2002, can be used not only as teacher training but also provides support and service for teachers' life-long learning in the rural areas.

4) Planning for curriculum: A good curriculum is relevant to the needs of children, parents, community and nation and provides suggestions and help for teachers to enable pupils to take multiple routes to success (Garrett, 1999:5 1). In China, especially in rural areas and the western regions, the contents of textbooks are often irrelevant and unfamiliar to children. Learning is still focused on the passive memorization of textbooks and a style of teaching and learning is driven by the examination format as well, as an examination is the only way to assess teaching and learning achievements. To improve the quality of basic education, the reform of the curriculum is inevitably evolved, including the contents of textbooks, the methodologies of learning and teaching as well as assessment. Great efforts have been made to carry out the piloting of new compulsory education curriculum. The new content of the curriculum focuses more on the vocational training to help peasants find or create jobs and also further facilitate the economic development of agriculture and farming in rural areas. Furthermore, methodology of teaching and learning is transferring from examinationoriented to competence - oriented education, following up curriculum restricting and textbook compilation. Last but not least, the 'Programme for Modern Distance Education in Primary and Secondary Schools in Rural Areas' will be implemented as well. It will enable students in rural areas to share the best teaching resources, and will help 20 percent of the poorest students (some 24 million students) in the rural areas at basic education level (Zhou Ji, 2003).

\section{CONCLUSION}

The rich variety of materials concerned with quality of basic education and its improvement are presented in this paper. In reviewing quality of basic education, it is worth remembering that to improve the education of the children; great endeavors need to be contributed combining vision, commitment, professional and research evidence. However, the 'engine' in the drive for improved quality of basic education should be seen as the proper form of a national education plan. It involves a clear indication of policies, priorities within the education system, strategies to achieve the goals. It is clear from the case study that the achievement of the overall quality of education is dependent on the complete improvement of all facets both within the education system and external contexts.

\section{REFERENCES}

[1] Allsop, T. \&Brock, C. (Editors)1 993. Oxford Studies in Comparative. Education Key Issues in Educational Development Triangle Books

[2] Bennett, A. J. 1 999. Belize Primary Education Development Project. UNESCO

[3] Commonwealth Secretariat. 1991. Improving the Quality of Basic Education. Education Programme Commonwealth Secretariat

[4] Carron, G and Chau, N.T. 1996 The quality of primary schools in deferent development contexts. UNESCO Publishing International Institute for Educational Planning

[5] Chowdhury, R. A M. and Choudhury, K. R. (Editors)2001. A Question of Quality: State of Primary Education in Bangladesh Campaign for Popular Education The University Press Limited

[6] China Development Gateway 2004 Education in Rural Areas http: // www. Chinagate. Com. Cn/ English /14268. htm

[7] EDU. fi $16 . \quad 07.2002$. Basic education http://www.edu.Fi/English/pageLast. asp? Path=500,4699,4847.

[8] Gardner,R. 1985. Improving Quality in Primary Education in Developing Countries-Who Makes It Happen? Department of International And Comparative Education

[9] Garrett, R. and Smith, B.(Editors)1999. Turning Aid Policy into Practice: Operationalising NORAD's Principles Bristol Papers In Education Comparative and International Studies

[10] Hawes, H. and Stephens, D. 1990. Questions of Quality Primary Education and Development. Longman Group Ltd.

[11] Kellaghan, T. and Greaney,V. 2001. Using Assessment to Improve the Quality of Education Paris 2001 UNESCO: International Institute for Educational Planning

[12] Lockheed, E. M. and Verspoor,M. A. 1991. Improving Primary Education in Developing Countries The World Bank Publication Oxford University Press

[13] MakWati'G, Audinos, B. and Lairez, T. 2003. The role of statistics in improving quality of basic education in Sub-Saharan Africa http: // www. Adeanet. Org/biennial2003/papers/C Nesis ENG final. pdf

[14] Ministry of education, P. R. C. 27. 05. 2004 Statistics Report on Development of Education in China in 2003 http: //www. Moe.Edu. $\mathrm{cn} /$ edoas / websitel 8/inf05515. Htm

[15] UNESCO, 1982. Concerns and Challenges in Educational Development UNESCO Regional Office For Education In Asia And The Pacific, Bangkok

[16] UNESCO, 1993. Increasing and improving the quality of Basic Education The 900 Schools programme: improving the quality of primary schools in impoverished areas of Chile International Institute for Educational Planning(Established by UNESCO)

[17] UNESCO, 2002. Education For All Global Monitoring Report 2002 http: //www.unesco.Org / education / efa / monitoring/ pdf/ Monitoring_2002/EFAGMR 1-2_chapter2. Pdf

[18] UNESCO, 2003. Improving Performance in Primary Education: A Challenge to the Goals of Education for All.

[19] Wolff,L., Schiefelbein, E. and Valenzuela, J. 1994. Improving the Quality of Primary Education in Latin America and the Caribbean; Toward the 21 Century The World Bank Washington, D. C.

[20] World Bank Foreign Investment September 6, 1994 China----Basic Education in Poor/Minority Areas http: //www. Worldbank. Org. cn /English/content/683u1 148366. Shtml.

[21] Xie Guodong and Wang Songtao.2000. Eliminate Illiteracy and Spread Primary Education Educational research, P.R.C. 2000, No.6 http: // www.moe.edu.cn / edoas / website 18 / level2. jsp?tablename $=780$.

[22] Zhou Ji. 2003 Providing education for over a billion people http://portal.Unesco.org/education/en/ev. php-URL ID=27733\&URL DO= DO TOPIC\&URL SECTION=201.html

[23] Zhou Ji. 2004 Full Implementation of The 2003-2007 Action Plan for Invigorating Education 1 http:// www.edu.cn / 20040324 / 3102182.shtml 